\title{
画質差を伴ったステレオ静止画像の画質評価モデルの検討
}

\section{Consideration of Quality Evaluation Model for Stereoscopic Pictures of Dis- parate Quality in Object and Background Area}

\author{
正会員堀田裕弘 ${ }^{\dagger}$, 学生会員荒田真司 ${ }^{\dagger}$, \\ 本田和博 ${ }^{\dagger}$, \\ 村井忠邦†, 正会員高松 衛 ${ }^{\dagger}$, 正会員 中嶋芳雄 ${ }^{\dagger}$
}

Yuukou Horita $^{\dagger}$, Shinji Arata $^{\dagger}$, Kazuhiro Honda $^{\dagger}$, Tadakuni Murai ${ }^{\dagger}$, Mamoru Takamatsu $^{\dagger}$ and Yoshio Nakashima ${ }^{\dagger}$

\begin{abstract}
The influence that picture quality differences give to the perceived overal! quality of the picture is examined when a stereoscopic picture is of a disparate quality in object and background area. A subjective assessment test used pictures for evaluation made by encoding several parameters. These pictures showed differences in stereoscopic objects and other background areas. The picture quality of the objects and the background areas was defined based on a the subjective assessment score, and an estimation method for assessing the overall picture quality was examined using the assessment scores. An objective picture quality evaluation model, constructed without using the origirial picture was also examined.
\end{abstract}

キーワード：スデレオ画像, 画質評価, 単一刺激法, NR 画質評価モデル

\section{1. まえがき}

テレビジョン画面の大型化・高画質化が進み, 現在で は，MPEG-2 有いたデジタルテレビ放送が実用化され ている。このような状況の中, 次世代の映像メディアと して，立体映像が最も有力な候補しなっている，立体映 像は, 従来の 2 次元映像に比べ, リアリティや臨場感な ど人間の高度な感性に訴えることができる。

この立体映像を効率よく通信・蓄積しようとする場 合，立体映像を符号化により情報圧縮を行わなければな らない。このとき，立体映像は符号化誤差によって劣化 し, この劣化が大きい場合, 立体映像の特徵を阻害する 原因となり，ユーザに不快感を与えてしまう。そのため, ユーザがどのくらいの劣化まで許容できるか, 符号化パ ラメータをどのように設定すればよいかなどのユーザの 立場に立つた映像品質に対する議論が重要である.

これまで，画像の品質を求めるために主観評価法が用 いられてきた。しかし，主観評価法は，人間が画像を評 価する方法なので, 多大な労力と時間を要してしまう。 そこで，符号化された立体画像の客観的な画質評価法の 開発が必要である。

2003 年 10 月 24 日, ヒューマンインフォメーション研究会で発表

2004 年 4 月 23 日受付, 2004 年 8 月 13 日再受付, 2004 年 9 月 3 日採録 †富山大学 工学部

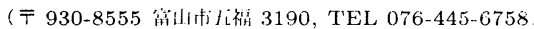

† Faculty of Engineering, Toyama University

(3190. Gofuku, Toyama-shi, 930-8555, Japar:
一方，JPEG2000 符号化に代表されるように，画像中 の ROI(Region of Interest) を優先的に高画質で符号化 する技術が用いられるようになってきている。よって， ROI を考慮したステレオ画像符号化に対する画質評価値 を推定するためには，部分的な画質が総合画質にどのよ うな影響を与えるのがを調べる必要がある。

そこで本研究では，立体視される物体部分とそれ以外 の背景部分を異なる符枵化パラメータで作成した画像を 用いて主観評価害験を行い，総合画質を推定する原画像 を用いない画質評価モデルを検討した。

\section{2. 主 観評価実 験}

符号化されたステレオ静止画像に対する主観的な品質 評価值 (MOS) を求めるために，主観評価実験を行った. 部分的な画質が総合画質にどのような影響を与えている のかを把握し，兴の総合画質の推定を行うために，評価 する原画像から立体視される部分とそれ以外の背景部分 とを領域分割し，二つの領域に異なった符号化パラメー 夕を設定して（同じ場合もある）得られた画像から，そ れぞれの部分を当てはめ合成して画像を作成し評価画像 とした ${ }^{11}$.

\section{1 実験条件}

ステレオ画像の評価実験の害験条件を表 1 に示す。.ま た，この評価実験で用いた単一刺激法の 5 段階評価尺度 を表 2 に示す.ディスプレイには，メガネを装着しない立 体ディスプレイである 10 インチ型 $3 \mathrm{D}$ 立体ビジョン $($ 兰 


\begin{tabular}{c|l}
\multicolumn{1}{c}{$\begin{array}{c}\text { 表 } 1 \text { 実験条件 } \\
\text { Viewing conditions. }\end{array}$} \\
\hline \hline 評価画像 & $\begin{array}{l}6 \\
\text { 種類 (LR:320×480 画素) } \\
\text { (cattle,goat,doll,peacock,cactus,woman) }\end{array}$ \\
\hline 符号化方式 & JPEG 符号化 (QS:7 種類) \\
\hline 視距離 & 立体に見える距離 $($ 約 $70 \mathrm{~cm})$ \\
\hline 照明 & なし (淮暗室) \\
\hline 評定者数 & 15 名 \\
\hline 評価方法 & 単一刺激法 \\
\hline
\end{tabular}

表 25 段階評価尺度

ITU-R quality scale

\begin{tabular}{c|l}
\hline \hline 品質 & 評価語 \\
\hline 5 & 非常に良い \\
\hline 4 & 良い \\
\hline 3 & 普通 \\
\hline 2 & 悪い \\
\hline 1 & 非常に悪い \\
\hline
\end{tabular}

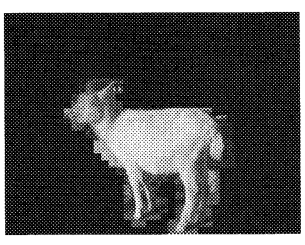

(a) 物体画像

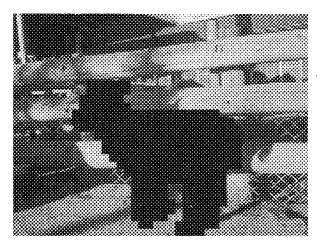

(b) 背景画像
図 1 評価画像の作成例 (goat) Assessment picture.

洋電機，THD-10P3) を用いた。 また, 評価実験により 得られる MOS の取りうる範囲を広く保つために, 各画 像に対して原画像と 6 種類の符号化パラメー夕を用いた. WWW 上で公開されている JPEG 符号化ソフト 2) では, 符号化パラメータとして Quality Scale(QS:1〜100)が用 いられ，この QS で ITU 勧告の量子化テーブルの值を 全体的にスケーリングすることにより符号量制御を行つ ている. 本論文では, この QS を符号化バラメータとす る. 今回の評価実験では, 先に行ってきた主観評価実験 の QS を参考にし， 6 種類の $\mathrm{QS}(10,15,27,37,55,79)$ を採 用した ${ }^{1)}$.

図 1 は，原画像"goat"の左画像に対する立体視される 部分とそれ以外の背景部分とを領域分割した処理結果の 例を示している.この処理を 6 種類の左右の原画像に対 し行う。各原画像に対して，立体視される物体部分とそ れ以外の背景部分に異なる符号化パラメー夕を設定 (同 じ場合もある)して JPEG 符号化し, 得られた画像の物 体・背景部分のそれぞれを種々あてはめ合成して評価画 像を作成した。このとき，ステレオ表示する左右画像で， 各背景部分は同じ符号化パラメー夕を用いており，また， 各物体部分も同様である. よって, 原画像を含む合計 294 枚のステレオ画像を用いて主観評価実験を行った。

\section{2 実験結果}

主観評価実験から得られた MOS から部分的な画質を 求め, 総合画質の推定に有効であると考えられるいくつ かの変数を用いてステップワイズ回帰分析を行った。

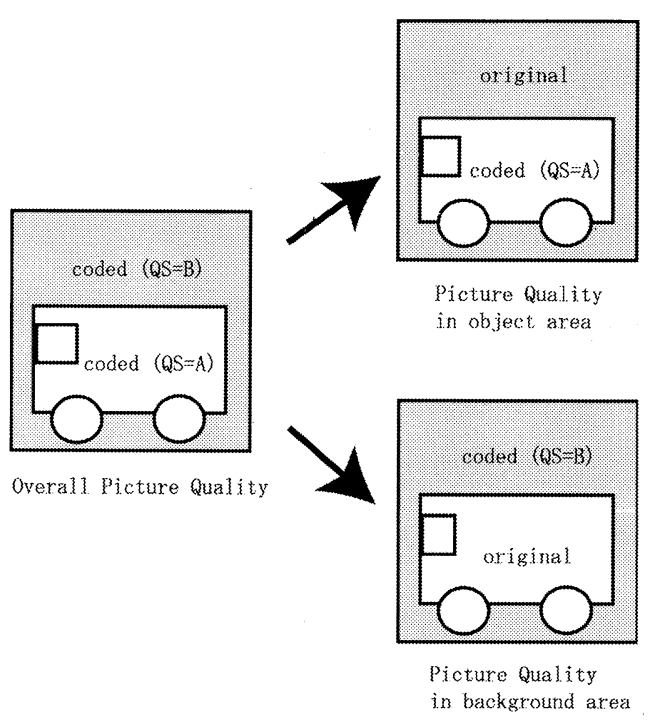

図 2 部分的な画質の定義 Definition of partial picture quality

\section{（1）回帰分析に用いる変数の定義}

これまでに，部分的に少化した画像の総合画質は劣化 部分から受ける主観的劣化量と产の主観的面積の積に よって詊価できることが示唆されている ${ }^{31}$ 。そこで，ス テレオ静止画像に挰いても，このような傾向を考慮して 検討を行なう，そのために回帰分析に用いる基本となる 変数を以下の上うに定義する，物体部分の符号化パラ メー夕 QS を A, 背景部分の QS を B とした場合の画像 について説明する(図 2).

・物体部分の画質評価值 $M O S_{f g}$ :物体部分を $\mathrm{QS}=\mathrm{A}$ で符号化し，背景部分を原画像としたステレオ静止画像 の主観評值值

・背景部分の画質詊価値 $M O S_{b g}$ : 背景部分を $\mathrm{QS}=\mathrm{B}$ で 符号化し，物体部分を原画像としたステレオ静止画像の 主観評価値

・物体部分の面積率 $S_{f g}$ :物体部分の面積が画像全体に 占める割合

- 背景部分の面積摔 $S_{b g}$ : 背景部分の面積が画像全体に 占める割合

\section{(2) 総合画質の推定}

先に定義した変数 $M O S_{f g}, M O S_{b g}, S_{f g}, S_{b g}$ を以下に 示すように色々組合せて, 独立变数として定めた.

$M_{O S}, S_{f g}, S_{b g}, S_{f g}, S_{b g}, M_{S_{f g}}+\operatorname{MOS}_{b g}, \operatorname{MOS}_{f g}-$ $\operatorname{MOS}_{b g}, \operatorname{MOS}_{b g}-\operatorname{MOS}_{f g},\left|\operatorname{MOS}_{f g}-\operatorname{MOS}_{b g}\right|,\left(\operatorname{MOS}_{f g}\right)^{2}$, $\left(M_{O S g}\right)^{2}, \operatorname{MOS}_{f g} M O S_{b g}, \sqrt{M O S_{f g} M O S_{b g}}, \operatorname{MOS}_{f g} S_{f g}$, $\operatorname{MOS}_{b g} S_{b g}, \operatorname{MOS}_{f g} \operatorname{MOS}_{b g} S_{f g} S_{b g}, \sqrt{M O S_{f g} M O S_{b g} S_{f g} S_{b g}}$

これらの独立変数と MOS を従属変数として，ステッ プワイズ回帰分析を行った。 その結果を次式で示す。こ こで, $M O S_{E V}$ は, 主観評価值 MOS の回帰式による推 定値を示している. 


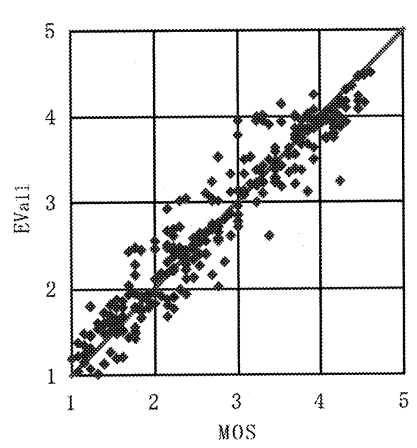

図 3 MOS $亡 M O S_{E V}$ 上の関係 Relation between MOS and $M O S_{E V}$.

$$
\begin{aligned}
& \text { 表 } 3 \text { 推定精度 } \\
& \text { Estimation accuracy. } \\
& M O S_{E V}=0.154+0.292\left(M O S_{f g}+M O S_{b g}\right) \\
& -0.299\left|M O S_{f g}-M O S_{b g}\right| \\
& +0.085 M^{\prime} O S_{f g} M O S_{b g}
\end{aligned}
$$

\begin{tabular}{c|c|c}
\hline \hline 平均誤差 & 最大誤差 & 相関係数 \\
\hline 0.21 & 0.99 & 0.96 \\
\hline
\end{tabular}

この式からもわかるように，面積率 $S_{f g}$ は採用されなかつ た.これは，MOS $f g, M O S_{b g}$ を先に述べた様に定義して いるので，面積の影響が既に考慮されて $M O S_{f g}, M O S_{b g}$ が得られていると考えられる. 式 (1) によって得られた 推定值 $M O S_{E V}$ と $M O S$ の関係を図 3 に示す. この式 の推定精度を表 3 に示す。 また, 式 (1) の第 2 項と第 3 項の回帰係数がほぼ同じであることより，物体部分と背 景部分のうち悪い方の画質を $M O S_{l q}$ とし, 前述した独 立変数に $M O S_{l q}$ を加え, 再度ステップワイズ回帰分析 を行うと，次式を得た。

$$
\begin{aligned}
\text { MOS }_{E V} & =0.091+0.652 M O S_{l q} \\
& +0.072 M O S_{f g} M O S_{b g}
\end{aligned}
$$

これより, 物体・背景領域で画質差があるステレオ静止: 画像の総合画質には物体・背景領域のうち悪い方の画質 の影響を強く受けることが示された，言い換えると，物 体・背景領域のうち良い方の画質を上げるより悪い方の 画質を上げた方が総合画質を向上させることができる。

また，左右画像で画質差のあるステレオ静止画像にお いても，本論文と同様に総合画質は，左右画像のうち画 質の悪い方の影響を強く受けることが報告されている ${ }^{4)}$.

\section{3. 画質評価モデル}

画質評価モデルは，原画像を使用する場合と用いない 場合の二つに大別されるが，本研究では，単一刺激法か ら得た MOSの推定を行うので，符号化画像のみから画 質を評価する原画像を用いないステレオ静此画像の画質 評価モデルを検討した:

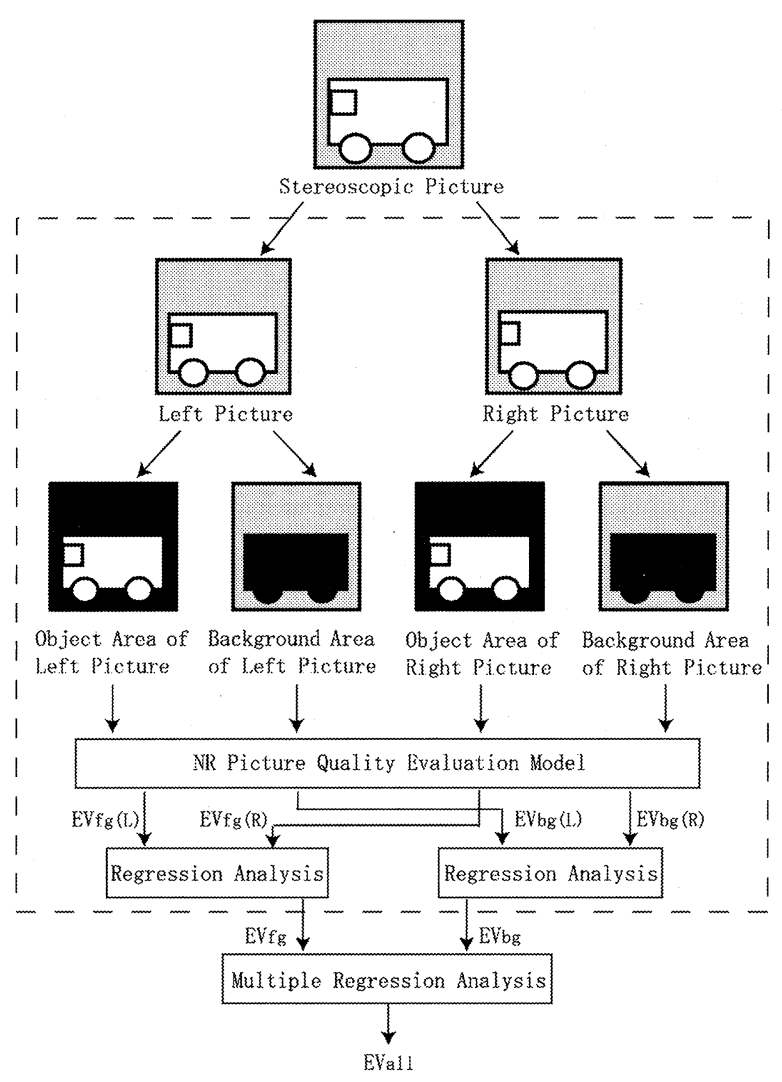

図 4 ステレオ静止画像つ画質評価モデル Stereoscopic picture quality evaluation model.

前述の実験結果では, 物体・背景部分で画質差がある ステレオ静止画像の総合画質は, 物体部分の画質と背景 部分の画質との積と物体・背景部分のうち悪い方の画質 で表せることが示された。このことを利用して，物体・ 背景部分の画質を画像から定量的に求め, 物体・背景部 分で画質差があるステレオ静止画像の客観的な画質評傈 モデル (図 4) の構築を検討した。

\section{1 評価モデルの計算手順}

画質評価モデルのおおまかな計算手順を説明する.

・ステレオ画像を構成する各左右画像を物体・背景部 分に分離する。

- 2 次元画像としての物体・背景部分の各左右画像に おける画質評価值を，原画像を用いない画質評価モデル (NR Picture Quality Evaluation Model)により求める。

$E V_{f g(L)}$ : 左画像の物体部分の画質

$E V_{f g(R)}$ : 右画像の物体部分の画質

$E V_{b g(L)}$ : 左画像の背景部分の画質

$E V_{b g(R)}$ : 右画像の背景部分の画質

・ステレオ画像としての物体・背景部分の画質評価值 $M O S_{f g}, M O S_{b g}$ (図 2 を参照) の推定值 $E V_{f g}, E V_{b g}$ を, $E V_{f g(L)}$ と $E V_{f g(R)}, E V_{b g(L)}$ と $E V_{b g(R)}$ をそれぞれ用い た回帰式により求める。

・物体・背景の画質評価値 $E V_{f g}, E V_{b g}$ から, ステレ 
才静止画像の総合画質の推定值 $E V_{\text {all }}$ を回帰式により求 める。このときの回帰式は式 (2) が基本となる。

\section{2 物体・背景部分の画質}

本論文では，既に提案されている 2 次元画像に対する 画質評価モデル ${ }^{5)}$ を用いて, 物体・背景部分の画質を求 める. この画質評価モデルでは, JPEG 符号化によって 発生するブロックノイズを特徴量としているので, 領域 の大きさや形に依存せずに画質を求めることができる.

(1) 原画像を用いない画質評価モデル

物体・背景部分の画質を求める画質評価モデル5) では, JPEG 符号化によって発生するブロックノイズを定量化 するために, 以下に示す特幑量を計算している.

まず，隣接する画素間での輝度差 $d_{h}$ を求め差分信号 とし, これを用いてブロックノイズ $B_{h}$, ブロック内の差 分信号の平均 $A_{h}$, ゼロ交差率 $Z_{h}$ を求める. ここで, $\mathrm{M}$ は画像の垂直方向の画素数, $\mathrm{N}$ は水平方向の画素数を表 している.

$$
\begin{aligned}
& B_{h}=\frac{1}{M([N / 8]-1)} \sum_{i=1}^{M} \sum_{j=1}^{[N / 8]-1}\left|d_{h}(i, 8 j)\right| \\
& A_{h}=\frac{1}{7}\left[\frac{8}{M(N-1)} \sum_{i=1}^{M} \sum_{j=1}^{N-1}\left|d_{h}(i, j)\right|-B_{h}\right] \\
& Z_{h}=\frac{1}{M(N-2)} \sum_{i=1}^{M} \sum_{j=1}^{N-2} z_{h}(i, j)
\end{aligned}
$$

ここで， $z_{h}$ は $d_{h}$ がゼロを通るときに 1 ，そうでないと きは 0 とする. 垂直方向についても同様の計算を行い, それらの平均によって特徵量 $\mathrm{B}, \mathrm{A}, \mathrm{Z}$ を計算し以下の式を 用いて一つの評点 $E V$ を得る.

$$
E V=\alpha+\beta B^{\gamma_{1}} A^{\gamma_{2}} Z^{\gamma_{3}}
$$

ここで, $\alpha, \beta, \gamma_{1}, \gamma_{2}, \gamma_{3}$ はパラメータである. 文献 7) で は, 本論文で用いたステレオ静止画像と同じ画像の 2 次 元画像を用いて主観評価実験を行っており，その主観評 価実験から得られた 2 次元画像の主観評価值 MOS と推 定值 $\mathrm{EV}$ との最大誤差が最小になるように $\mathrm{PSO}^{6)}$ でパラ メータの最適化を行った.

また, この画質評価モデルは, 当初, カラー画像の 画質評価を輝度情報のみで行っており, 非線形性も考慮 されていなかった，そこで，色情報を考慮するために， YUV 色空間において，隣接する画素間の $\mathrm{Y}, \mathrm{U}, \mathrm{V}$ それぞ れの差を求め, それらの 2 乗平均を色情報を考慮した差 分信号 $d_{h}$ とした。この差分信号を用いて, B,A,Z を求 め, これらから, 画質の推定を行った $(\text { 図 } 5)^{8)}$. 本論文 では，色差情報を用いてこの評価モデルから画質評価值 を得るが, 符号化パラメータの数は輝度のモデルと同じ で、B,A,Z の計算手順も同じである.

この画質評価モデルを画像の物体・背景部分にそれぞ れ用いることによって，左右画像それぞれについて物体・ 背景部分の画質を定量的に求める.

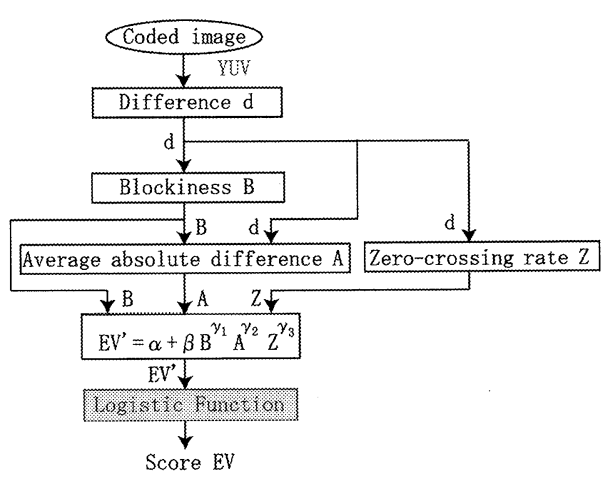

図 5 原画像在用いなら画質評価モデル（色差情報, ロジスティツ ク関数を考慮)

NR(No Refference) picture quality evaluation model.

\section{3 総合画質の推定}

前述した実験結果と, 既存の画質評価モデルを用いて ステレオ静止画像の画質評価モデル図 4 を構築する.

この画質評価モデルでは, まず, 物体・背景部分で画 質差があるステレオ静止画像の総合画質は, 物体部分の 画質と背景部分の画質との積と物体・背景部分のうち悪 い方の画質で表せるので, 前述した原画像を用いない画 質評価モデルを用いて, 物体部分の画質と背景部分の画 質を定量的に求める.

ステレオ静止画像での左右画像間の画質の差を考慮す るために，まず，左右画像の画質を，前述した原画像を 用いない画質評価モデルを用いて求める. そして, 次に, 左右画像の画質や，物体・背景部分の面積率を色々組合 せて独立変数とし，ステレオ静止画像の物体・背景部分 の画質を従属変数としてステップワイズ回帰分析を行つ た.この処理を物体・背景部分に行うことでステレオ静 止画像の物体・背景部分の画質を求めた。 その物体部分 の画質 $\left(E V_{f g}\right)$, 背景部分の画質 $\left(E V_{b g}\right)$ を次式に示す.

$$
\begin{aligned}
E V_{f g}= & 0.409+1.676 E V_{f g(L)}-1.856 E V_{f g(L)} S_{f g} \\
& -0.163 E V_{f g(L)} E V_{f g(R)} \\
& +0.36 E V_{f g(L)} E V_{f g(R)} S_{f g} \\
E V_{b g}= & 0.928+0.694 E V_{b g(L)}
\end{aligned}
$$

これらの結果より, 物体部分の画質には, 面積率が採用 され，背景部分の画質には，面積率が採用されず，2 次 元画像の画質評価モデルで得た推定値用いることで表せ ることが示された。このことは, 文献》における, 分散 分析の結果の「ステレオ画像と 2 次元画像の画質の差は, 物体部分の面積率によって異なる.」ということと,「背 景部分は, 2 次元画像のように劣化が見える.1という結 果と一致している.

次に, 物体部分の画質 $E V_{f g}$ と背景部分の画質 $E V_{b g}$ との積と物体・背景部分のうち覀い方の画質 $E V_{l q}$ を独 立変数, ステレオ静止画像の総合画質の推定值 $E V_{a l l}$ を 従属変数として重回帰分析を行った，その結果を式 (9) 


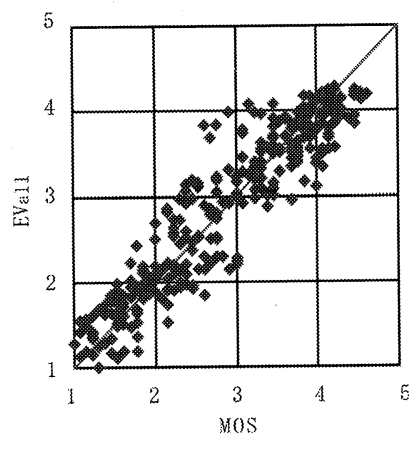

図 6 MOS 亡 $E V_{\text {all }}$ 亡の関係 Relation between $M O S$ and $E V_{a l l}$.

表 4 推定精度

Estimation accuracy.

\begin{tabular}{c|c|c}
\hline \hline 平均誤差 & 最大誤差 & 相関係数 \\
\hline 0.29 & 1.21 & 0.93 \\
\hline
\end{tabular}

に示す.

$$
E V_{\text {all }}=0.053+0.579 E V_{l q}+0.091 E V_{f g} E V_{b g}
$$

式 (9)によって得られた推定値 $E V_{\text {all }}$ と MOS の関係 を図 6 に示す．また，この式の推定精度を表 4 に示す.

ここで, 平均誤差 0.29 は, MOS の $95 \%$ 信頼区間の平 均が 0.43 であることから,この画質評価モデルは精度良 く推定できていることがわかる. しかし, 最大誤差が 1 を超える画像もあった。

\section{4. むすび}

本論文では，ステレオ静止画像において部分的な画質 が総合画質にどのような影響を与えるのかを調べるため に，立体視される物体部分とそれ以外の背景部分とで符 号化パラメー夕を変えて画像を作成し，これを合成した 画像に対して, 単一刺激品質尺度法を用いて主観評価実 験を行った。実験で得られた主観評価値から部分的な画 質を定義し，それらを用いてステレオ静止画像の総合画 質を推定する方法を検討した，その結果，物体部分の画 質と背景部分の画質を用いることで，ステレオ静止画像 における総合画質を精度良く推定でき，総合画質には物 体・背景部分のうち悪い方の画質が強く影響しているこ とが示された。

また, この結果より, 物体・背景部分の画質を符号化 画像のみから定量的に求め, 画質差を伴ったステレオ静 止画像の総合画質を客観的に求める画質評価モデルの構 築在検討した，その結果，物体部分の画質は，左右画像 の画質と物体部分の面積率を用いることで表すことがで き, 背景部分の画質は, 2 次元画像の画質を用いること で表すことができた。

しかし，この画質評価モデルによる推定精度は，平均 誤差だけを見ると精度良く推定できるが，最大誤差を見 ると誤差が 1 を超える画像があり, 画像による依存性が

あった.

今後の予定としては，ステレオ静止画像特有の歪みを 画質評価モデルに加えることで, 推定精度の改善を行っ ていくつもりである.

\section{〔文献〕}

1）櫛田, 堀田, 本田, 村井: “物体・背景領域で画質の異なるステレオ静止画像の 画質評価値の推定”，映情学技報, HIR2002-123, pp.15-18(Oct 2002)

2) "The Independent JPEG Group's JPEG software", ftp://ftp.uu.net/graphics/jpeg/jpegsrc.v6b.tar.gz

3）大塚作一:“部分的に劣化した画像の品質評価”,テレビ誌, 42, 8 pp857-859 (1988)

4) 堀田, 櫛田, 本田, 村井, 高松, 中嶋: “左右画像で画質差のあるステレオ静止 画像に打ける画質推定”，映情学誌，57, 12, pp1737-pp1739 (2003)

5) Zhou Wang, Hamid R.Sheikh and Alan C.Bovik:"No-Reference Perceptual Quality Assessment of JPEG Compressed Innage", IEEE ICIP-2002 (Sep., 2002)

6) J. Kennedy and R. Eberhart:"Particle Swarm Optimization", Proceedings of IEEEthe International Conference on Neural Networks, Perth, Australia, pp. 1942-1948,(Nov. 1995).

7) 堀田, 荒田, 本田, 村井, 高松, 中嶋: “単一刺激法を用いた $3 \mathrm{D} / 2 \mathrm{D}$ 符号化画 像の画質評佂値の比較”, 映情学誌, 58, 10, pp1457-pp1460 (2004)

8）荒田，堀田：本田，村井,: “原画像を用いない画質評価モデルの精度改善”, 2003 年電子情報通信学会総合大会, D-11-47 (2003)
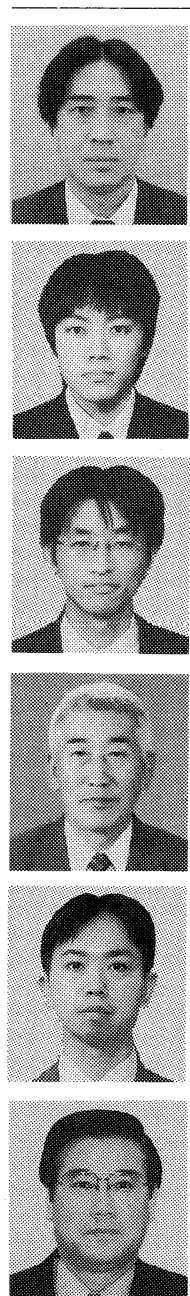

堀苗裕弘 1984 年, 長岡技術科学大学工学部電気. 電子システム工学課程卒業. 1986 年, 同大学院修士課程 了. 同年, 富士通 (株) 入社. 1993 年, 富山大学工学部講 師. 1998 年, 同助教授。酒質評価, コンピュータビジョン, 感性情報処理等の研究に従事. 工学博士．正会員.

荒等真司 2003 年, 富山大学工学部電気電子シス テム工学科卒業. 現在, 同大学院博士前期課程在学中, 又 テレオ画像の画質俨価の研究に従事. 学生会員.

笨笛笛博 1995 年, 富山大学工学部電子情報工学 科卒業. 1997 年, 同大学院博士前期課程了. 同年, 同大学 工学部技官. 電磁界, 音場, 流体の数值シミュレーション に関する研究に従事.

村井䖝邦 1967 年, 富山大学文理学部理学科卒業。 同年, 同大学工学部教務員. 1971 年, 同助手. 1987 年, 同講師. 1990 年, 同助教授. 1991 年, 同教授. 工学博士. 電磁界, 音場, 流体の数值シミュレーションに関する研究 に徒事.

翯淞衛 1995 年, 雷山大学工学部電子情報工学: 科卒業. 1997 年, 同大学院博士前期課程了. 2000 年, 闹 大学院博士後期課程了. 同年, 富山大学工学部知能情報工. 学科勤務. 2002 年, 富山大学工学部講師. 視覚情報処理, 色彩工学, 照明工学等の研究に従事. 工学博士. 正会真.

中嶋芳雄 1980 年, 東京工業大学大学院博士課程 了. 1993 年, 富山大学工学部助教授。1998 年, 同教授. 視覚情竍工学, 人間工学, 色彩工学, 照明工学, 交通視環 境工学，都市景観評価・設計に関する研究に従事：工学博 土. 正会員. 